\title{
PERFORMANCE EVALUATION OF END SUCTION, SINGLE STAGE, RADIAL DISCHARGE CENTRIFUGAL PUMP IN TURBINE MODE OPERATION
}

\author{
Ajit Singh Aidhen \\ Research Scholar, Mechanical Engineering Department, Raffles University, \\ Neemrana, India \\ Sandeep Malik \\ Assistant Professor, Computer Science and Engineering Department, Raffles University, \\ Neemrana, India

\section{Chavan Dattatraya Kishanrao} \\ Principal, Siddhant College of Engineering, \\ Sudumbare, Pune, India
}

\begin{abstract}
Pump as Turbine (PAT) provides a cost-effective alternative to conventional hydro turbines for high terrain rural areas where grid supply is not feasible. PAT technology is simple, low in cost and easy to harness. End suction centrifugal pumps are readily available as compared to conventional custom made hydro turbines. This paper presents theoretical, numerical and experimental study of radial discharge centrifugal pump in hydro turbine mode. Experimental setup is used to investigate performance of radial discharge end suction mono block centrifugal pump in pump and turbine mode and the results are compared with theoretical and numerical results. Performance characteristic of mono block pump of specific speed $20.28\left(\mathrm{~m}, \mathrm{~m}^{3} / \mathrm{s}\right)$ in turbine mode operation are determined through experiment. The experiment results reveal suitability of using a mono block centrifugal pump in hydro turbine mode. The results confirm that the pump in hydro turbine mode operate at higher heads and discharge as compared to the pump mode operation. BEP (best efficiency point) for the pump in hydro turbine mode is lower than in pump mode operation. Correlations proposed by earlier researchers for performance prediction of pump in hydro turbine mode are also tested.
\end{abstract}

Keywords: Pump as Turbine (PAT), Pico hydro, Renewable energy.

Cite this Article: Ajit Singh Aidhen, Sandeep Malik, Chavan Dattatraya Kishanrao. Performance Evaluation of end Suction, Single Stage, Radial Discharge Centrifugal Pump in Turbine Mode Operation. International Journal of Mechanical Engineering and Technology 11(1), 2020, pp. 61-72.

https://iaeme.com/Home/issue/IJMET?Volume=11\&Issue $=1$ 


\section{INTRODUCTION}

Rural electrification enhances the life quality for rural communities. The supply of electricity to high terrain rural areas by extending national grid is not feasible as it is uneconomical. Offgrid Pico or micro hydro electrification system requires appropriate technology and are required to be easy to maintain, economically feasible, simple and safe to use. To this concern Pump as Turbine (PAT) proves to be a viable solution. PAT although has lower efficiency as compared with commercial custom made hydro turbines, but since pumps are available in a wide range of head and discharge, PAT based Pico hydro power generation is economical and practical. Pump in hydro turbine mode provide higher output energy as they can handle higher flow rates. [1].Pump manufacturers provide performance curves for pump mode operation of their pumps but not for turbine mode, hence selecting a pump suitable for a particular site is a challenge. [2]. PATs behavior can be predicted through simulation analysis, theoretical frameworks and experimentation. The experimental test rig was setup to conduct performance analysis and the results were compared with simulation and theoretical predictions. The testing procedure for PAT performance are similar to pump test standard, ISO 9906:2012.End suction, radial discharge centrifugal pump with specific speed of $20.28\left(\mathrm{~m}, \mathrm{~m}^{3} / \mathrm{s}\right)$, was used in the experiment and the performance characteristic of the PAT were determined.

\section{THEORETICAL, NUMERICAL AND EXPERIMENTAL INVESTIGATION}

Many researchers and authors have presented theoretical and experimental studies predicting performance of centrifugal pumps in turbine mode [3]. The pump mode-based prediction simply requires pump performance basic information of flow rate, head and the efficiency, from which turbine mode performance can be predicted by simple calculations. Theoretical methods involve head and flow correction factors based on pump mode to predict PAT performance. Relations based on pump mode BEP for PAT performance prediction were developed by Stepanoff [4], Childs [5], Sharma [6] .Specific speed number relates to head, discharge speed of the pump and the geometry. Some researchers proposed relations based on the specific speed of the pump [7], [8], and [9]. The theoretical prediction methods have not provided very reliable solution in predicting PAT performance. The results obtained through theoretical methods need to be ascertained by experimental methods.

\section{NUMERICAL INVESTIGATIONS ON PAT}

Turbo machinery flow has high degree of complexity as it is three dimensional and involves turbulence, cavitations and unsteadiness. Initially the performance prediction methods of PAT were based on theoretical and experimental analysis where semi-empirical correlations were proposed from those obtained in pump mode. The methods proposed to predict accurate turbine performance are not $100 \%$ reliable for various types of pump of different specific speed range [10]. CFD in recent years has emerged as a tool of great importance in the prediction of the flow through turbo machines. Computational power, speed and accuracy of numerical methods and computational machines have led to development of CFD.

Accuracy of mesh and the boundary conditions applied definitely affect the results of numerical simulation. Higher accuracy mesh and applied boundary conditions result in better "converged" solution. Convergence (Residual values) is only a small part of ensuring valid solution. It is a must to carry out a mesh independence study i.e. to confirm that the solution is independent of the mesh resolution. Mesh independence study is executed with initial mesh and convergence of residual error is checked and points of values of interest are checked for steady solution finally imbalances should be $<1 \%$. If the simulation results are not satisfactory the procedure is repeated with a refined mesh. 
The point values are then compared, if they are same as earlier, the previous mesh was accurate, if the point values are not in acceptable limits use a further refined mesh. The steps are repeated until a solution independent of the mesh is reached. The smallest mesh that gives mesh independent solution should be used, this reduces simulation run time.

The results of numerical analysis however should not be dependent on the resolution of mesh. So if the results do not change with mesh density mesh independence is achieved. A good practice to verify the turbulence model is that the produced results are in line with experimental data. Many researchers have proposed that $\mathrm{k}-\varepsilon$ model, SST, RNG k- $\varepsilon$ and the Realizable k- $\varepsilon$ turbulence models are suitable for the internal flow simulation of the of a centrifugal pump. These turbulence models simulate the flow in a low specific speed pump with best agreement with the experimental results. In the presented study Realizable k- $\varepsilon$ turbulence model is used. The four meshes used for grid independence study with the mesh count are:

Mesh - A: Total Mesh Count - 853,649

Mesh - B: Total Mesh Count - 1,380,220

Mesh - C: Total Mesh Count - 1,889,906

Mesh - D: Total Mesh Count - 2,478,636
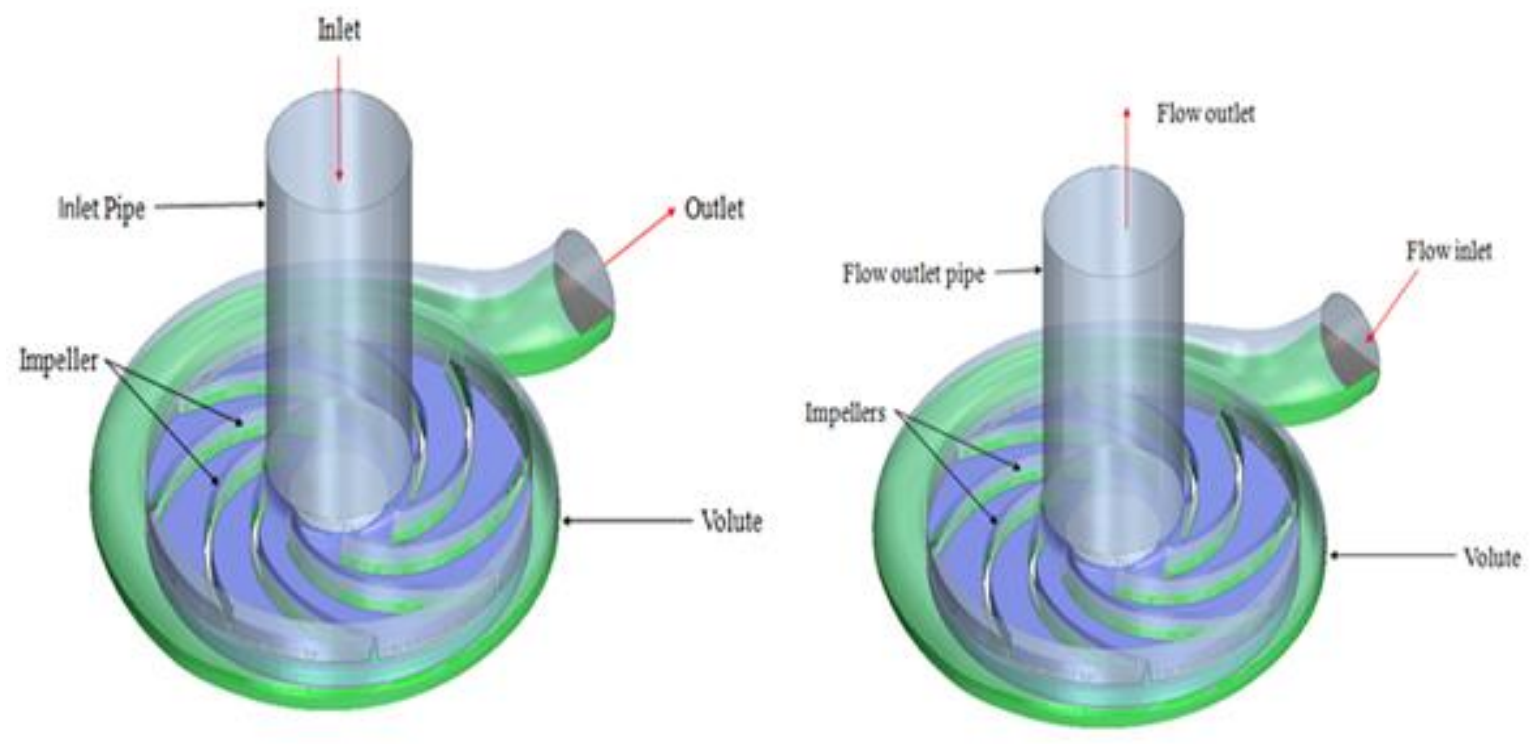

Figure 1. Pump model geometrical details (Left), Turbine model geometrical details (Right)

The validation of the results is done by comparing the simulation results in the pump mode with the manufacturer provided curve. Mesh - B produced the closest approximation with least error. Table -1 gives the percentage error in the results with the four meshes used. Mesh - B was used for further simulations.

The simulations were run for pump mode at its rated RPM of 1400 and were also run for the same pump in turbine mode at four different RPM 1200, 1300, 1400 and 1500.The results of simulation were compared with experimentally obtained results. Correlations proposed by earlier researchers were used to predict the performance of PAT. 


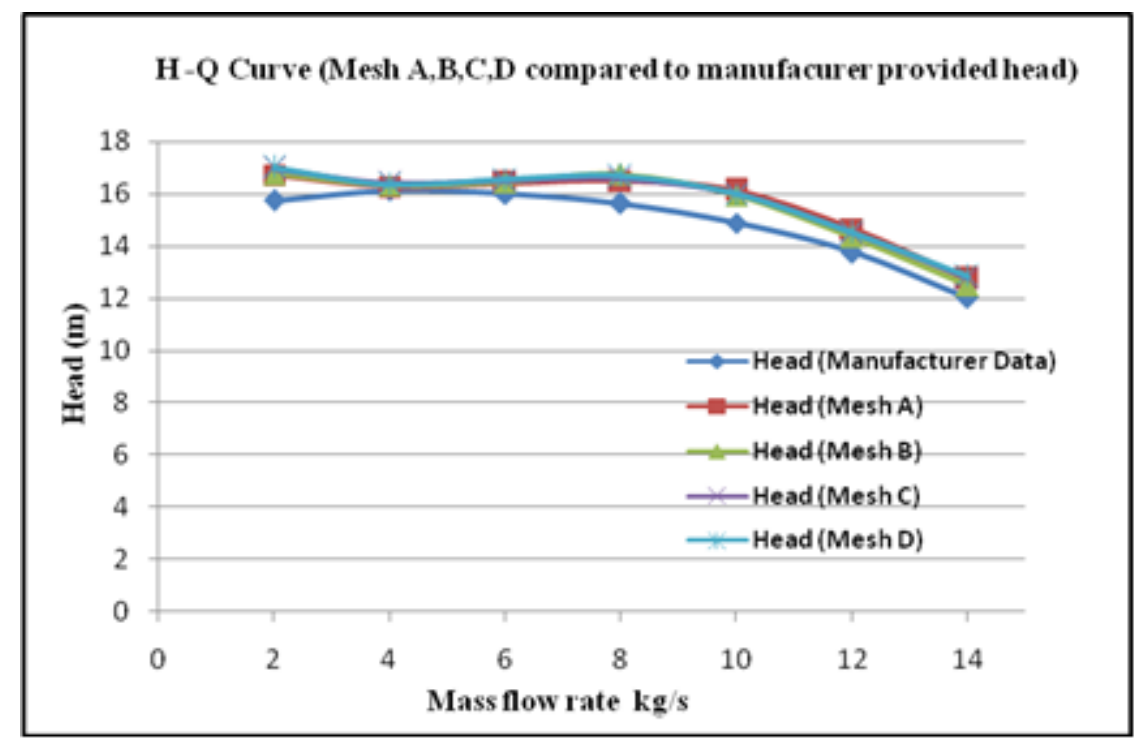

Figure 2. Grid Independence with four meshes

Table 1 Percentage difference between manufacturer data and CFD Simulation

\begin{tabular}{|c|c|c|c|}
\hline Mesh - A & Mesh - B & Mesh - C & Mesh - D \\
\hline$-6.12 \%$ & $-6.38 \%$ & $-7.77 \%$ & $-7.97 \%$ \\
\hline$-0.93 \%$ & $-1.22 \%$ & $-1.80 \%$ & $-1.43 \%$ \\
\hline$-2.60 \%$ & $-2.73 \%$ & $-3.10 \%$ & $-3.31 \%$ \\
\hline$-5.57 \%$ & $-7.12 \%$ & $-5.96 \%$ & $-6.78 \%$ \\
\hline$-8.44 \%$ & $-7.17 \%$ & $-7.39 \%$ & $-7.51 \%$ \\
\hline$-6.50 \%$ & $-4.25 \%$ & $-5.43 \%$ & $-5.63 \%$ \\
\hline$-6.07 \%$ & $-4.13 \%$ & $-6.43 \%$ & $-7.03 \%$ \\
\hline
\end{tabular}

\section{EXPERIMENTAL ANALYSIS}

The PAT is similar to Francis turbine in the sense that it converts energy from flowing water. The fluid in the turbine mode is directed into the pump through the discharge side and flows out from the pump suction side. The mechanical power is the product of angular velocity $(\omega)$ and torque $(\tau)$ in PAT mode where the impeller rotational speed is $(\mathrm{N}) \mathrm{Rev} / \mathrm{min}$.

Mechanical power $=($ torque $)$ (angular velocity)

$P_{\text {mechanical }}=\frac{2 \pi N \tau}{60}($ watts $)$

The pressure difference across the PAT is denoted by $\mathrm{H}$.

$\mathrm{PAT}_{\text {input hydraulic power }}=\rho g Q H$ (watts)

Where $(\rho)$ is water density, $(\mathrm{g})$ is gravitational acceleration, $(\mathrm{Q})$ is flow rate and $\mathrm{H}$ is the pressure head.

The process of energy conversion encounters some mechanical and hydraulic losses and hence power losses. The efficiency of PAT is expressed as:

$$
\eta=\left(\frac{P_{\text {mechanical }}}{P_{\text {hydraulic }}}\right) \times 100=\frac{\frac{2 \pi N \tau}{60}}{\rho g Q H}
$$




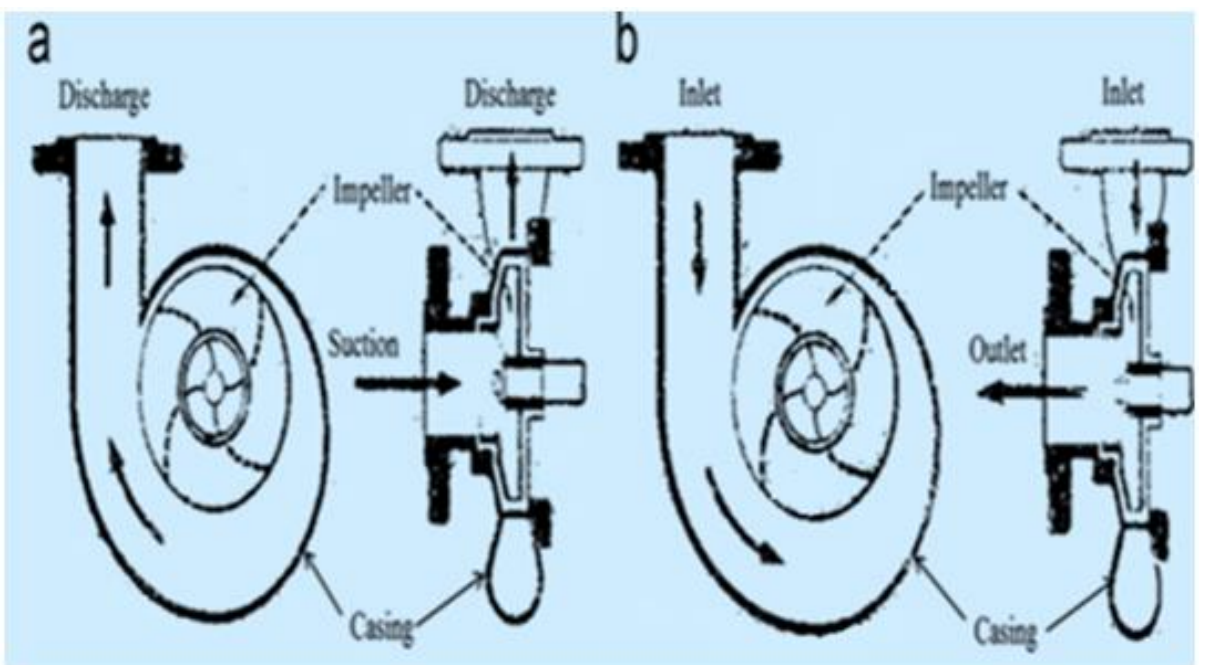

Figure 3. Centrifugal pump in (a) pump and (b) turbine modes [11]

Figure 3 shows the PAT concept. In reverse pump mode figure (b) the water enters to the volute casing inward in radial direction and leaves axially rotating the impeller of the pump. The direction of rotation of impeller in reverse pump mode is opposite to that of pump mode direction. Although this arrangement is similar to Francis turbine except for the absence of guide vane.

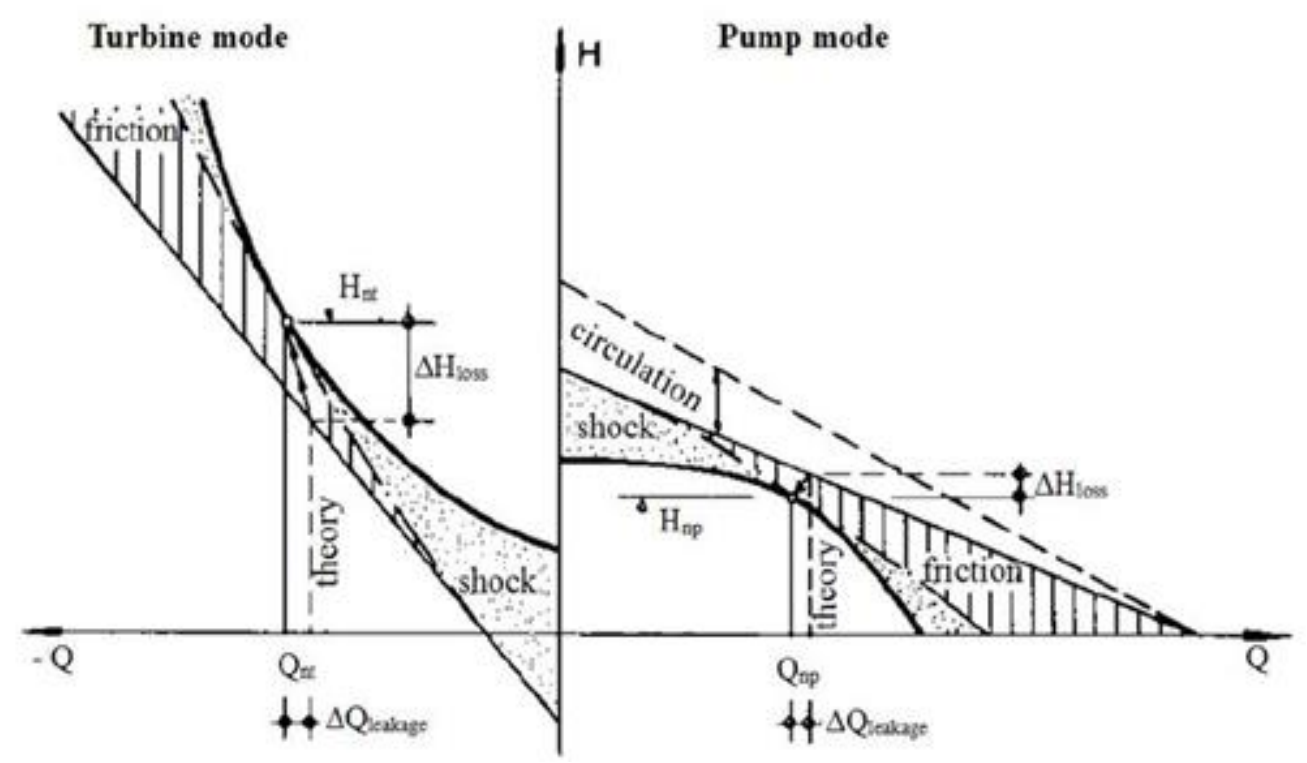

Figure 4. Hydraulic losses in (a) pump mode and (b) turbine mode (Chapallaz et al., 1992) [13]

Circulation losses exist due to the finite number of vanes. The circulation loss for PAT will be very small as it takes place at inner periphery of the impeller. Friction losses increase as the flow increases and are proportional to square of the flow. Mismatch in the flow direction, volute casing angle and the impeller blade angles leads to shock loss which leads to loss of efficiency. Shock losses are zero with design flow and are proportional to square of flow. Disc friction losses occur due to liquid trapped between impeller and casing. Further some water leaking from high pressure to low pressure results in loss of energy both in pump mode and PAT modes. 

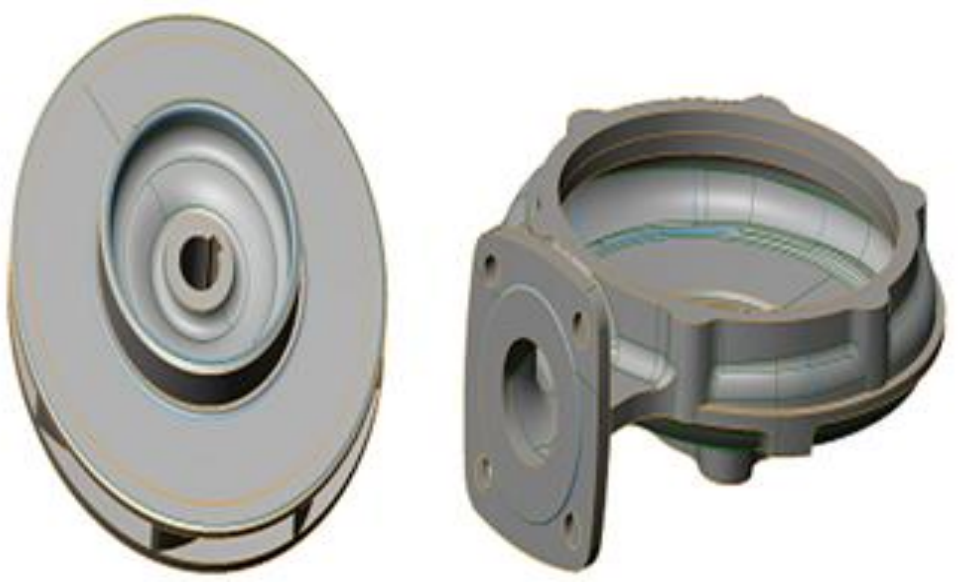

Figure 5. Solid geometry of pump used as turbine

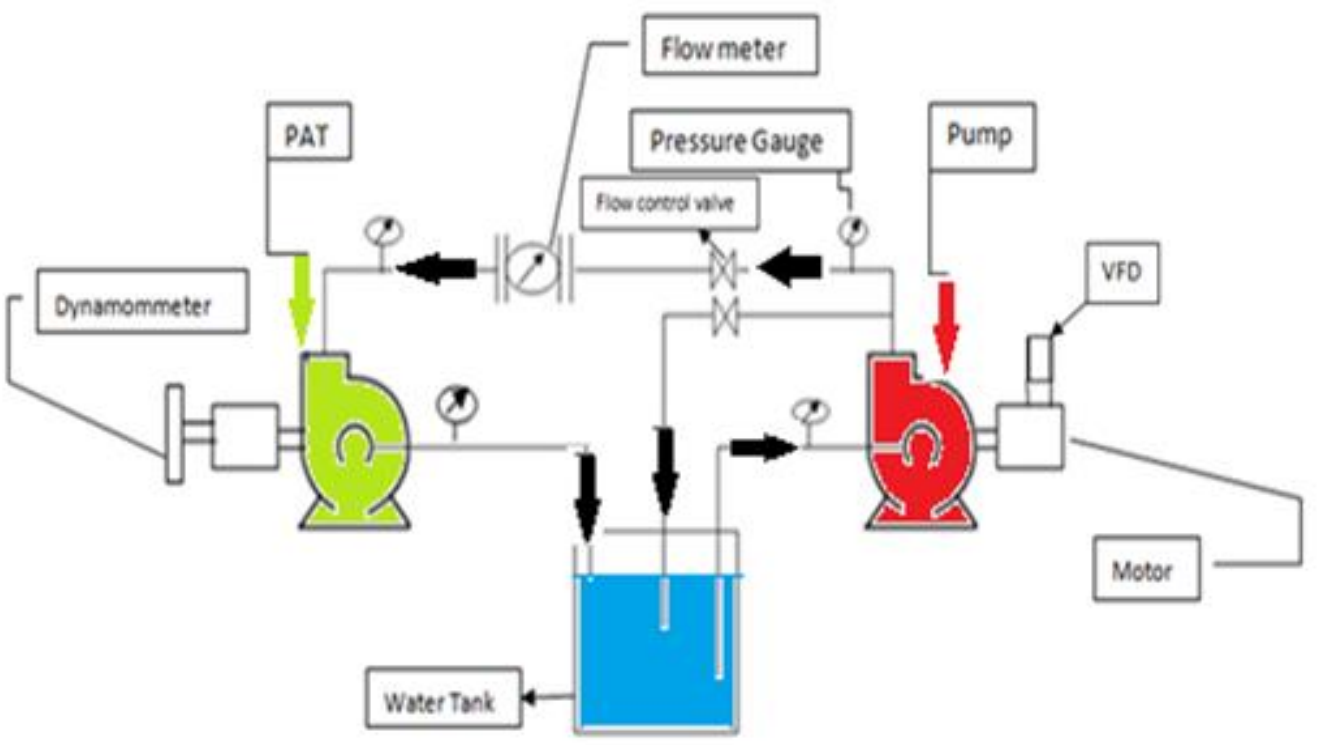

Figure 6. Schematic layout of the experimental test rig.

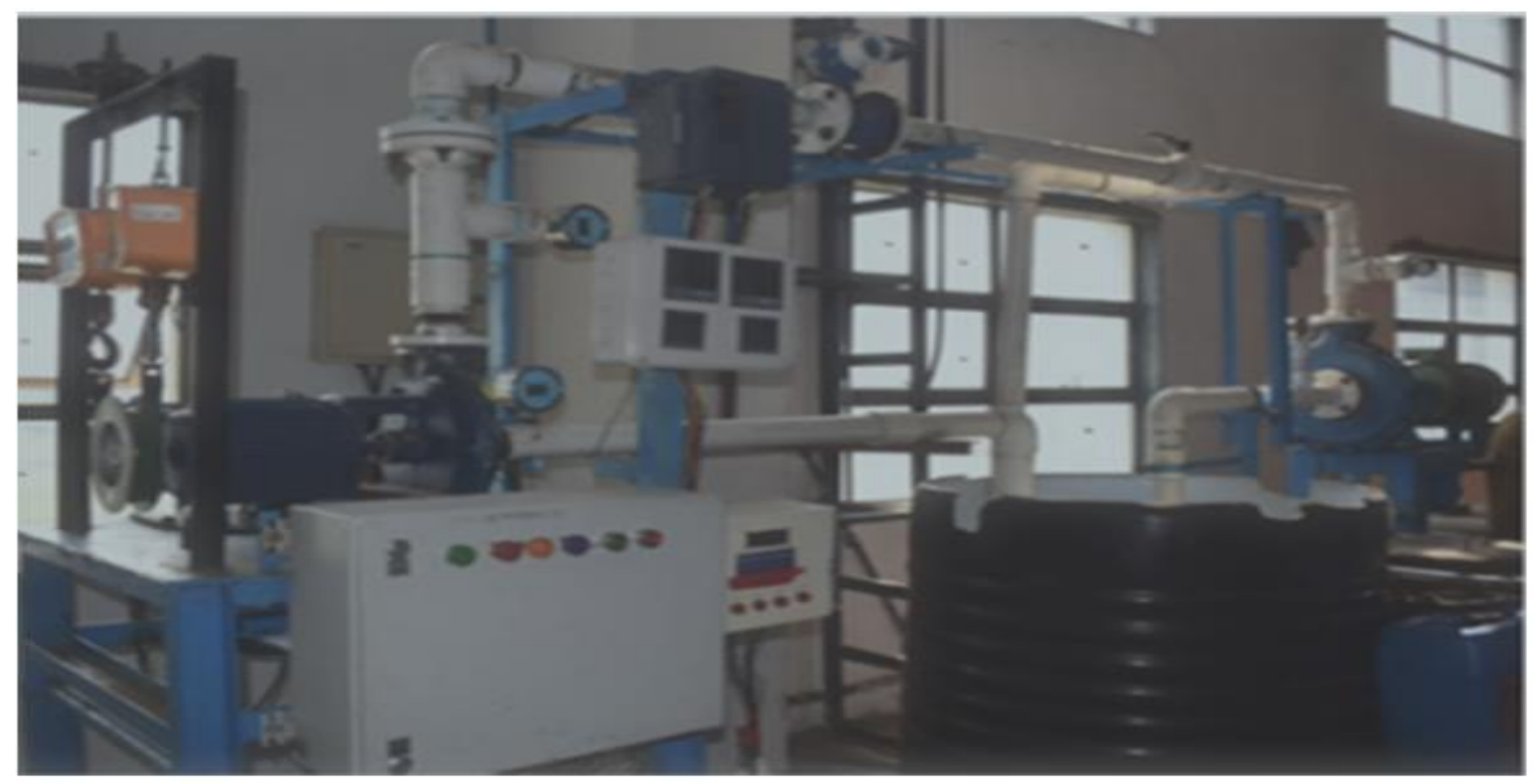

Figure 7. Picture of the actual test rig 
The Figure-6 and Figure-7 show Schematic layout and actual picture of the experimental test rig respectively. The experiment was run in pump mode at 1400 RPM and in turbine mode at four RPM 1200, 1300, 1400, 1500. Table -2 shows the details of the instumentation used with the test rig.

Table 2. Instumentation used with experimental test rig

\begin{tabular}{|l|l|l|}
\hline \multicolumn{1}{|c|}{ Instrument } & \multicolumn{1}{c|}{ Type } & \multicolumn{1}{c|}{ Accuracy } \\
\hline Flow meter & EUMAG Electromagnetic flow meter & $\pm 0.5 \%$ of flow \\
\hline Digital pressure gauge & PG/DPG-20 & Accuracy: $\pm 25 \%$ F.S \\
\hline Rope brake Dynamometer & 0-50 kg, digital display & $+/-0.5 \%$ \\
\hline Speed Digital Tachometer & Non Contact Photo Electric & $+/-0.05 \%$ \\
\hline Variable Frequency Drive & Fuji VFD 10HP & $\begin{array}{l} \pm 0.01 \% \text { of max. } \\
\text { frequency }\end{array}$ \\
\hline
\end{tabular}

\section{THEORETICAL PREDICTION OF PAT PERFORMANCE}

Based on BEP in pump mode and pump specific speed number many researchers have proposed relations to predict the turbine mode parameters, however the results obtained through models show a scope of further research. To predict the best efficiency point under reverse operation mode some authors relate the prediction factors $h$ and $q$, where

$\mathrm{h}=H_{B E P, T} / H_{B E P, P}$ and $\mathrm{q}=Q_{B E P, T} / Q_{B E P, P}$ to the pump specific speed under pump mode operation.

Specific speed number, $\mathrm{N}_{\mathrm{S}}=\mathrm{NQ}^{0.5} / \mathrm{H}^{0.75}$

Specific speed number relates ' $\mathrm{N}$ ' the rotational speed, 'Q' the discharge and 'H' the head at BEP and the geometry. Methods based on pump specific speed number hence are better compared to methods based on pump mode BEP in predicting PAT performance. Table summarizes these models:

Table 3 Performance prediction methods by various researchers [12]

\begin{tabular}{|c|c|c|c|c|}
\hline Reference & Criteria & Head correction Factor (h) & Discharge correction factor (q) & Remarks \\
\hline $\begin{array}{l}\text { Stepanoff } \\
1957\end{array}$ & BEP & $1 / \eta p$ & $1 / \sqrt{\eta_{\mathrm{P}}}$ & $\begin{array}{l}\text { Accurate for } \\
\text { Ns: } 40-60\end{array}$ \\
\hline $\begin{array}{l}\text { Childs } \\
1962\end{array}$ & BEP & $1 / n_{\mathrm{P}}$ & $1 / \eta_{\mathrm{P}}$ & $* * *$ \\
\hline $\begin{array}{l}\text { Hancock } \\
1963\end{array}$ & BEP & $1 / \mathrm{n}_{\mathrm{k}}$ & $1 / \eta_{\mathrm{l}}$ & $* * *$ \\
\hline $\begin{array}{l}\text { Grover } \\
1980\end{array}$ & $\begin{array}{l}\text { Specific } \\
\text { speed }\end{array}$ & $2.693-0.0229 \mathrm{Nst}$ & $2.379-0.0264 \mathrm{Nst}$ & $\begin{array}{l}\text { Applied for } \\
\text { Ns: } 10-50\end{array}$ \\
\hline $\begin{array}{l}\text { Hergt } \\
1987\end{array}$ & $\begin{array}{l}\text { Specific } \\
\text { speed }\end{array}$ & $1.3-\left(6 / \mathrm{Nst}^{-}-3\right)$ & $1.3-(1.6 / \mathrm{Nst}-5)$ & $* * *$ \\
\hline $\begin{array}{l}\text { Sharma } \\
1985\end{array}$ & BEP & $1 / \mathrm{n}_{\mathrm{P}}^{1.2}$ & $1 / \eta_{\mathrm{P}^{0}}^{0.8}$ & $\begin{array}{l}\text { Applied for } \\
\text { Ns: } 40-60\end{array}$ \\
\hline $\begin{array}{l}\text { Schmiedl } \\
1988\end{array}$ & BEP & $-1.4+\left(2.5 / \mathrm{n}_{\mathrm{hP}}\right)$ & $-1.5+\left(2.4 / \mathrm{n}_{\mathrm{h}} \mathrm{P}^{2}\right)$ & $* * *$ \\
\hline $\begin{array}{l}\text { Alatorre } \\
\text { Frenk }\end{array}$ & BEP & $1 /\left(0.85 \eta_{\mathrm{P}}^{5+0.385)}\right.$ & $0.85 \mathrm{n}_{\mathrm{P}}^{5}+0.385 / 2 \mathrm{\eta}_{\mathrm{P}} 9.5+0.205$ & $* * *$ \\
\hline $\begin{array}{l}\text { Sharma } \\
1998\end{array}$ & BEP & {$[\mathrm{Ng} / \mathrm{Nm}]^{2} \mathrm{x}\left[1.1 / \mathrm{\eta}_{\mathrm{p}^{1.2}}\right]$} & {$[\mathrm{Ng} / \mathrm{Nm}] \times\left[1.1 / \mathrm{np}^{0.8}\right]$} & $\underset{=240 \times \mathrm{fg}}{\mathrm{Ng}-\mathrm{N}}$ \\
\hline
\end{tabular}


Ajit Singh Aidhen, Sandeep Malik, Chavan Dattatraya Kishanrao

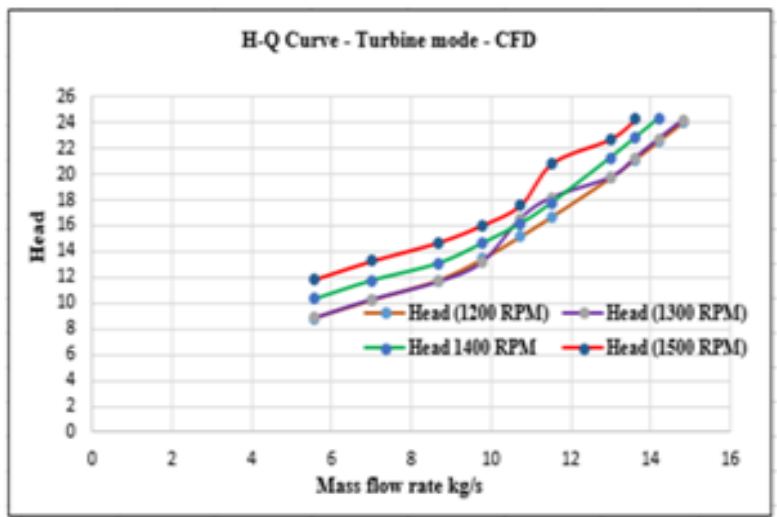

Figure 8. H - Q curve Turbine mode - CFD

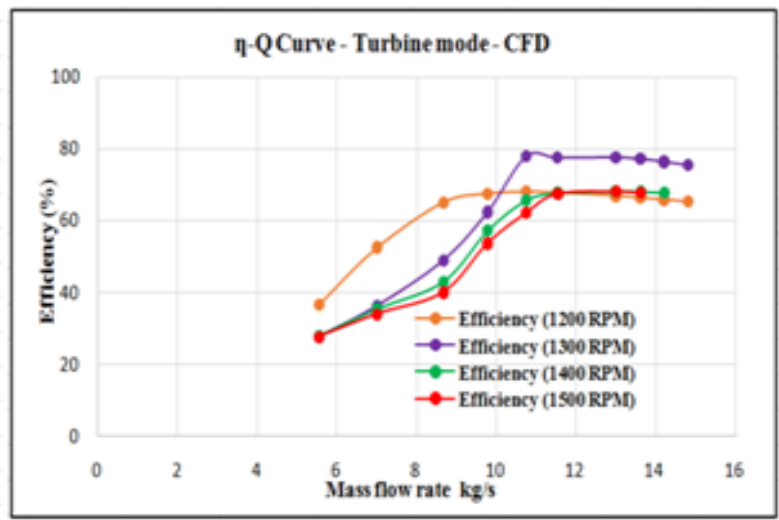

Figure 9. $\eta-Q$ curve Turbine mode - CFD

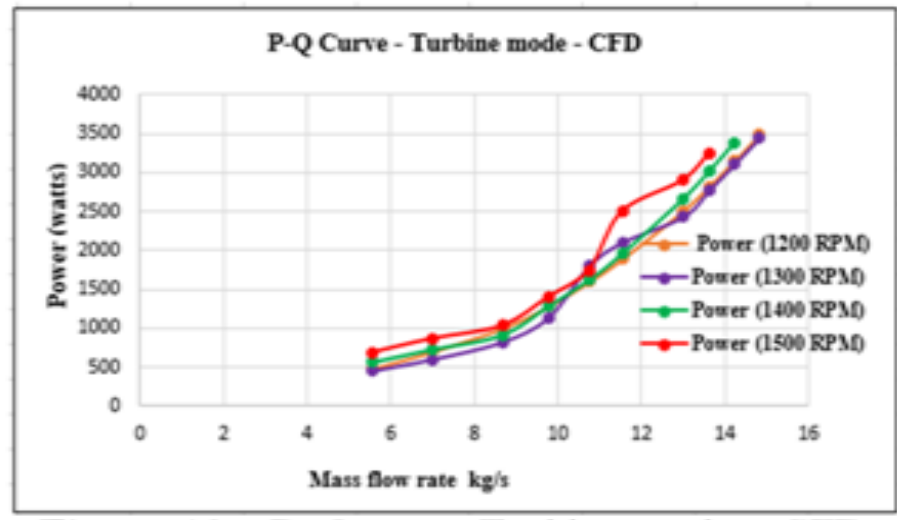

Figure 10. P- $\mathrm{Q}$ curve Turbine mode - CFD
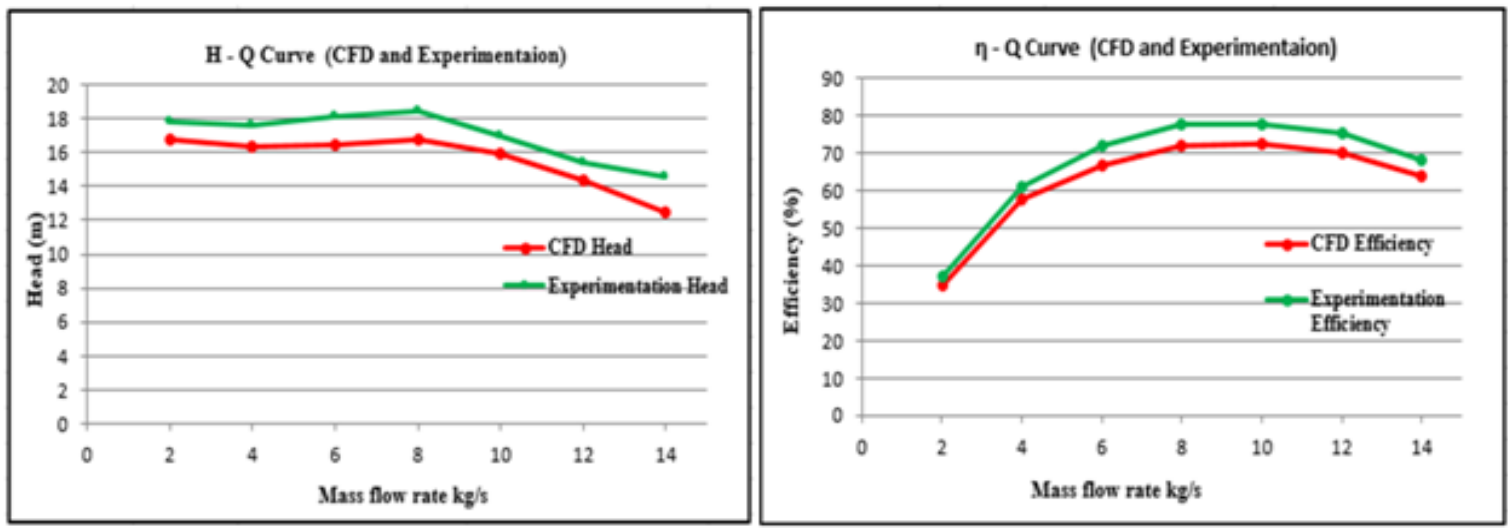

Figure 11. Pump mode 1400 RPM CFD and experimentation comparison
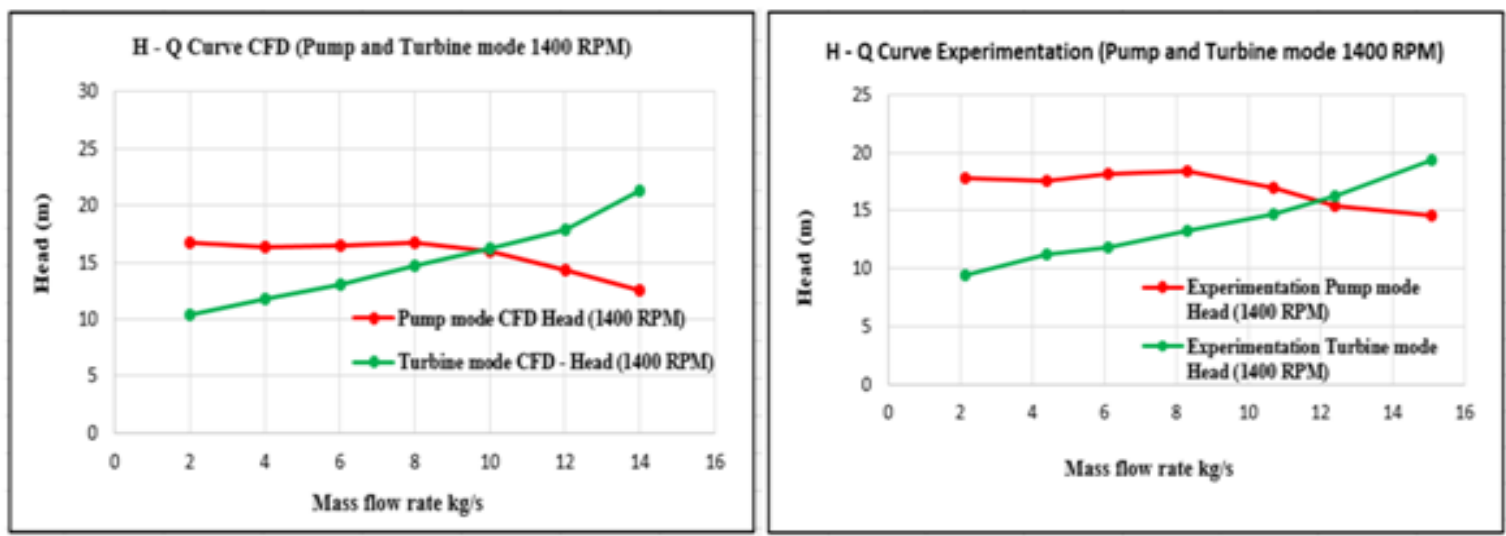

Figure 12. Pump and Turbine mode 1400 RPM H-Q curve CFD and Experimentation comparison 
Performance Evaluation of end Suction, Single Stage, Radial Discharge Centrifugal Pump in Turbine Mode Operation
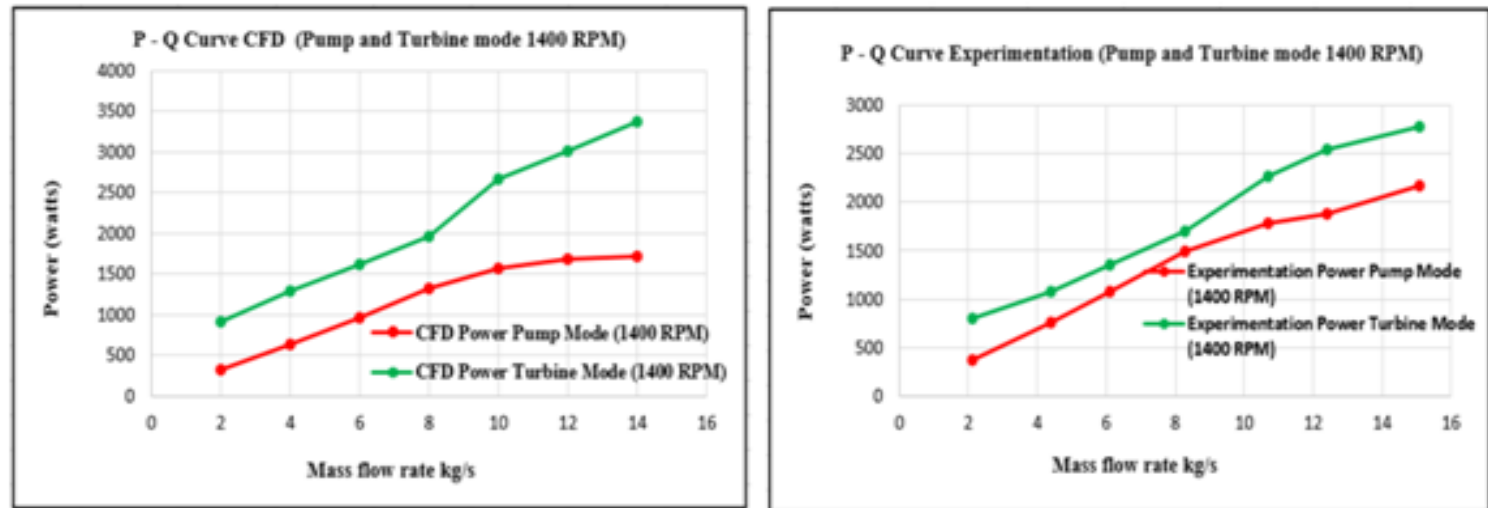

Figure 13. Pump and Turbine mode 1400 RPM P-Q curve CFD and Experimentation comparison
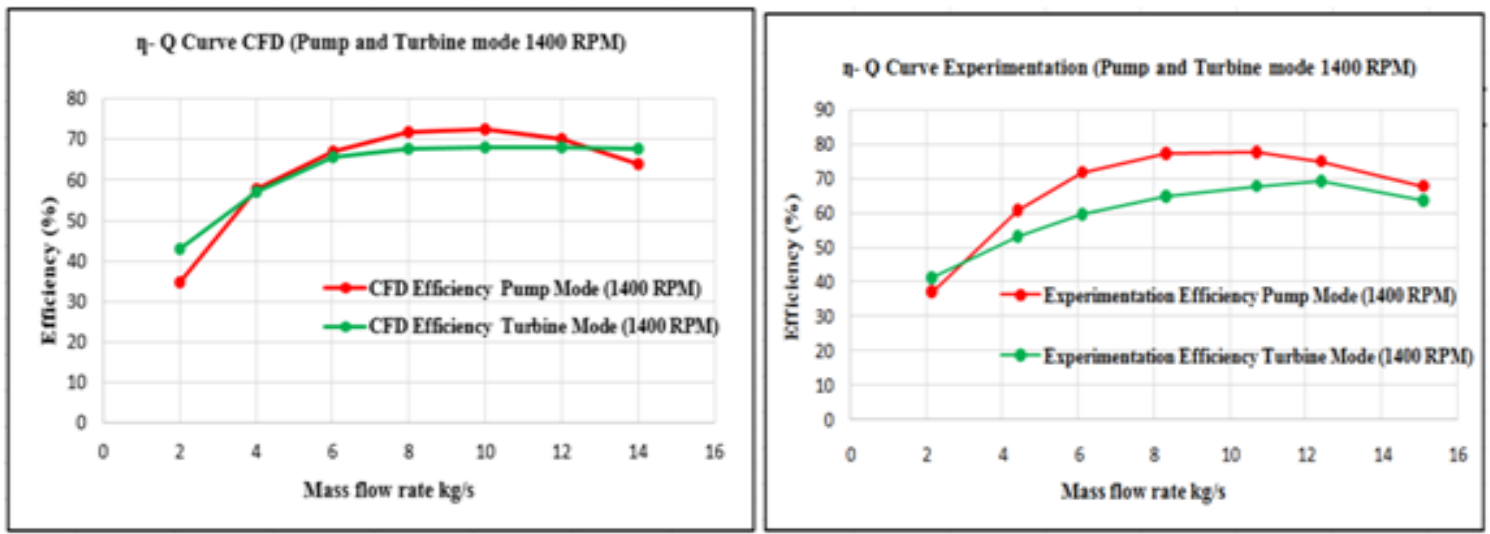

Figure 14 Pump and Turbine mode 1400 RPM n-Q curve CFD and Experimentation comparison

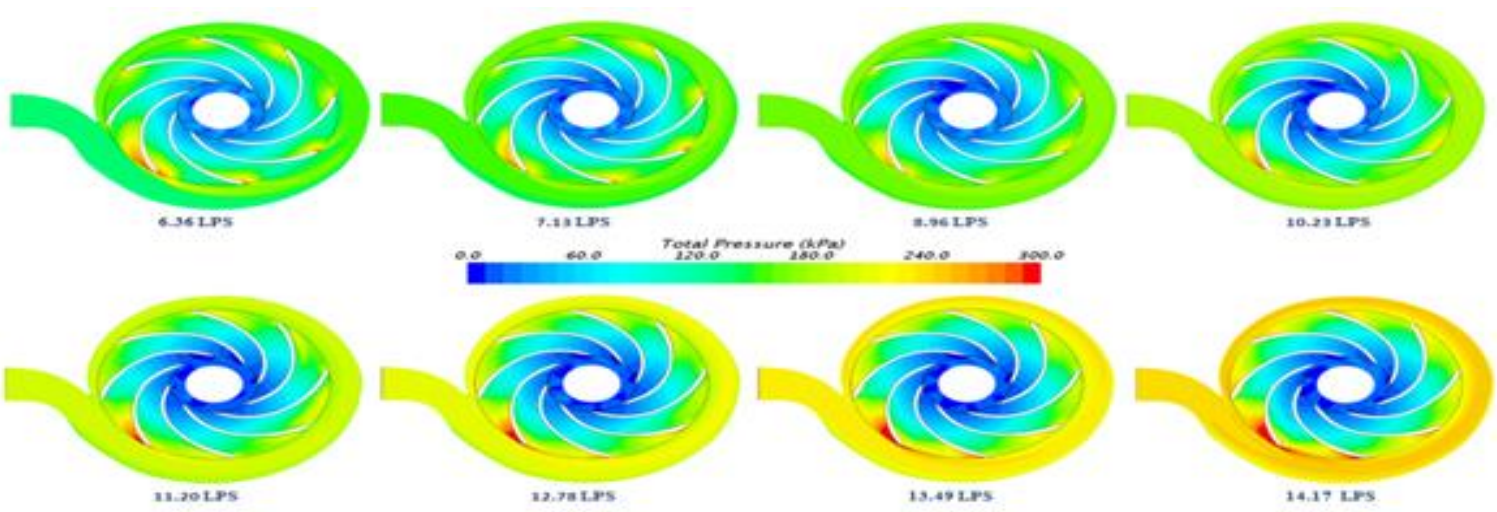

Figure 15. Velocity color plot Turbine mode 1400 RPM

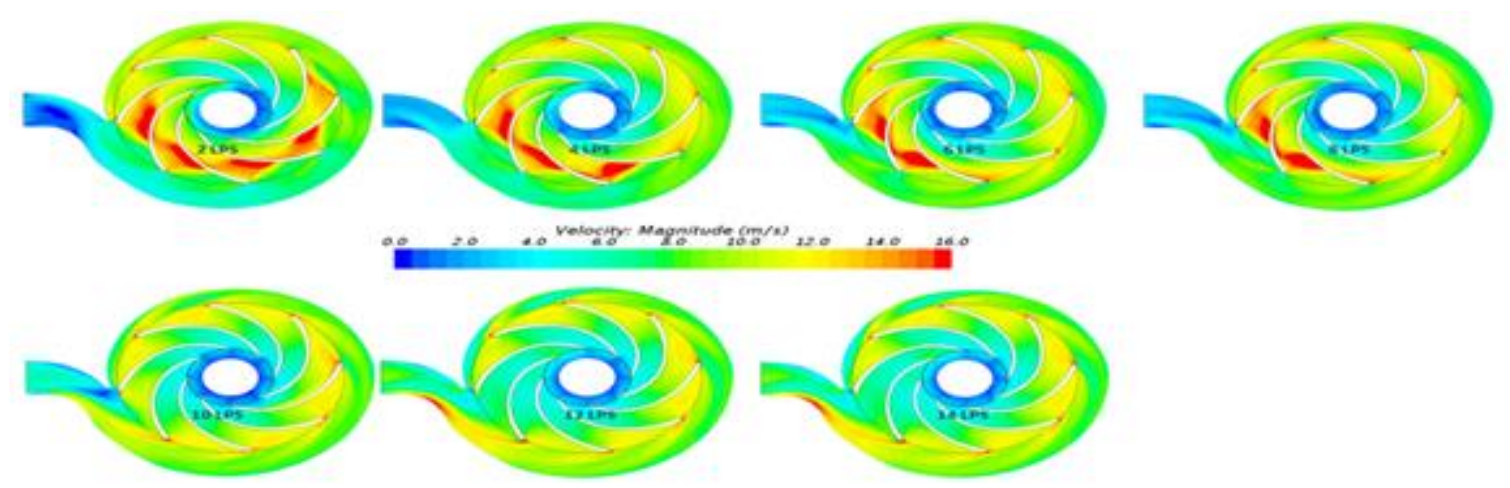

Figure 16. Velocity color plot Pump mode 1400 RPM 


\section{RESULTS AND DISCUSSIONS}

The experimentation revealed that the centrifugal pump can be run in turbine mode satisfactorily without any major concerns. The PAT readings were taken for four different RPM, 1200,1300,1400,1500 and pump mode readings were taken at rated RPM 1400.The experiment results show that the pump operates at higher heads and discharge values in turbine mode. The BEP in turbine mode was lower than BEP in pump mode. The BEP of the tested pump in turbine mode at pump rated RPM was $68.1 \%$ with head and flow of $21.2 \mathrm{~m}$ and $12.8 \mathrm{l} / \mathrm{s}$ respectively. Figure 8-10 show the head, power and efficiency curves in turbine mode with four different RPM 1200, 1300, 1400 and 1500. The BEP for 1200,1400 and 1500 RPM is close to $68 \%$ but is achieved at higher head and mass flow rate for higher RPM as seen in Table 5. The BEP at 1300 RPM through CFD in turbine mode was $77.9 \%$ but the same was not studied through experimentation. The characteristic curves of head, discharge, power and efficiency in pump and PAT modes by experimental and CFD methods are shown in Figures. 12-14. The error in CFD and experimental readings of Head, Mass flow and efficiency for both pump and turbine mode is observed to be less than $10 \%$. The percentage error are tabulated in Table 3 and Table 4. Figure 11 shows CFD and experimentation result comparison in Pump mode at 1400 RPM, the error in CFD and experimental readings are tabulated in Table -3.The error \% at BEP and for other readings is less than 9\%, however for low mass flow rate and low head it is found to be more than $10 \%$. The CFD prediction for head, flow and efficiency is higher for pump mode and lower for turbine mode. Correlations proposed by researchers were tried to predict turbine mode BEP, many correlations proposed did not produce satisfactory results the correlations of head and discharge correction factors by Stepanoff (1957), Childs (1962), and Sharma (1985) however were close in approximation.

Table $3 \%$ Error - CFD and Experimentation - Turbine Mode - 1400 RPM

\begin{tabular}{|c|c|c|}
\hline \% Error - Mass flow & \% Error - Head & \% Error - Efficiency \\
\hline$-9.09 \%$ & $-8.97 \%$ & $-12.90 \%$ \\
\hline$-2.59 \%$ & $-4.82 \%$ & $-12.43 \%$ \\
\hline$-3.25 \%$ & $-9.86 \%$ & $-3.95 \%$ \\
\hline$-7.36 \%$ & $-9.17 \%$ & $-6.64 \%$ \\
\hline$-8.08 \%$ & $-9.09 \%$ & $-8.99 \%$ \\
\hline$-4.51 \%$ & $-8.98 \%$ & $-4.14 \%$ \\
\hline$-6.91 \%$ & $-8.65 \%$ & $-0.44 \%$ \\
\hline$-8.05 \%$ & $-8.27 \%$ & $1.91 \%$ \\
\hline$-8.96 \%$ & $-9.86 \%$ & $-6.06 \%$ \\
\hline
\end{tabular}

Table $4 \%$ Error - CFD and Experimentation - Pump mode - 1400 RPM

\begin{tabular}{|c|c|c|}
\hline \% Error Flow & \% Error Head & \% Error Efficiency \\
\hline $6.00 \%$ & $6.2 \%$ & $7.00 \%$ \\
\hline $9.97 \%$ & $7.8 \%$ & $5.55 \%$ \\
\hline $1.52 \%$ & $10.1 \%$ & $7.72 \%$ \\
\hline $3.68 \%$ & $9.9 \%$ & $7.72 \%$ \\
\hline $6.99 \%$ & $6.6 \%$ & $7.29 \%$ \\
\hline $3.26 \%$ & $7.4 \%$ & $7.52 \%$ \\
\hline $7.84 \%$ & $16.8 \%$ & $6.32 \%$ \\
\hline
\end{tabular}


Performance Evaluation of end Suction, Single Stage, Radial Discharge Centrifugal Pump in Turbine Mode Operation

Table 5 Turbine Mode BEP- CFD - (Mass flow, Head, Power \& Efficiency) at RPM 1200, 1300, 1400,1500

\begin{tabular}{|c|c|c|c|c|}
\hline RPM & Mass Flow Rate $\mathbf{( k g / s )}$ & Head $(\mathbf{m})$ & Power (watts) & Efficiency (\%) \\
\hline 1200 & 10.7 & 15.2 & 1598.8 & 68.1 \\
\hline 1300 & 11.1 & 16.6 & 1798.5 & 77.9 \\
\hline 1400 & 12.8 & 21.2 & 2663.1 & 68.1 \\
\hline 1500 & 13.0 & 22.7 & 2902.8 & 68.4 \\
\hline
\end{tabular}

\section{CONCLUSION}

This paper presents theoretical, numerical and experimental study carried out on end suction radial discharge centrifugal pump with specific speed number $20.28(\mathrm{~m}, \mathrm{~m} 3 / \mathrm{s})$ and rated RPM 1400.The experimental trial were carried out in pump mode and turbine mode. The verification of numerical results was carried out by comparing the CFD results with those obtained through experimentation. CFD results were in acceptable agreement with experimental data for pump mode and turbine mode at best efficiency point and also in partload. The CFD prediction for head, flow and efficiency is higher for pump mode and lower for turbine mode. In both modes the $\%$ error is less than $9 \%$. Correlations proposed by researchers were tried to predict turbine mode BEP, many correlations proposed did not produce satisfactory results, the correlations of head and discharge correction factors by Stepanoff (1957), Childs (1962), Sharma (1985) however were close in approximation. The study carried out suggests that there is scope for better correlations for theoretical prediction of turbine mode parameters. The CFD simulations results also show scope of refinement.

\section{REFERENCES}

[1] Nautiyal H, Kumar A. Reverse running pump analytical, experimental and computational study: a review. Renewable and Sustainable Energy Review; vol.14:p2059-67, 2010.

[2] Jain SV, Patel RN. Investigations on pump running in turbine mode:a review of the state of-the-art. Renewable and Sustainable Energy Reviews, Elsevier; vol.30:p841-68, 2014.

[3] Nautiyal H, Varun V, Kumar A, Yadav SYS. Experimental investigation of centrifugal pump working as turbine for small hydropower system.Energy Science and Technology, vol.1:p79-86, 2011.

[4] Stepanoff AJ. Centrifugal and axial flow pumps, design and applications. New York: John Wiley and Sons, Inc; 1957.

[5] Childs S.Convert pumps to turbines and recover HP. Hydrocarb Process Pet Refin; vol.41:p173-4, 1962.

[6] Sharma RK. Small hydroelectric projects-use of centrifugal pumps as turbines. Bangalore, India: Kirloskar Electric Co; 1984.

[7] Gopalakrishnan S. Power recovery turbines for the process industry. Proceedings of the third international pum symposium [Houston]. Texas A \&M University; p.3-11, 1986

[8] Diederich H. Verwendung von kreiselpumpen als turbinen. Frankenthal, Germany: KSBTechn Ber; p.30-6, 1967.

[9] Grover K. Conversion of pumps to turbines. Katonah, New York: GSA Inter corp; 1982.

[10] Binama Maxime, Su Wen-Tao, Li Xiao-Bin, Li Feng-Chen, Wei, Xian-Zhu, An Shi,. "Investigation on pump as turbine (PAT) technical aspects for micro hydropower schemes: A state-of-the-art review," Renewable and Sustainable Energy Reviews, Elsevier, vol. 79(C), p 148-179, 2017. 
[11] P.Vasanthakumar et al., Investigation Of Centrifugal Pump as Turbine: A Review Report, International Journal of Engineering Research \& Technology, Vol. 3, p 2287- 2292, 2014.

[12] Jain SV, Patel RN. Investigations on pump running in turbine mode: a review of the stateof-the-art. Renewable and Sustainable Energy Rev; vol. 30:p841-68, 2014.

[13] J- M Chapallaz, P. Eichenberger, G. Fischer, http://skat.ch/book/manual-on-pumps-usedas-turbines-vol.11 